(Reprinted in U. S. A. from Transactions of 1942

of the American Geophysical Union)
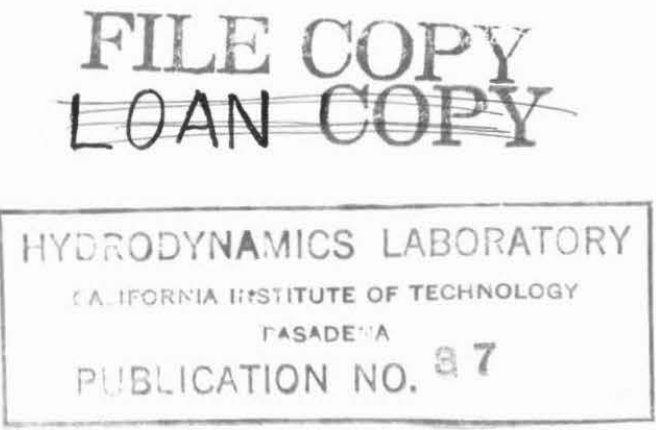

\title{
SCOUR-CONTROL AND SCOUR-RESISTANT DESIGN FOR HYDRAULIC STRUCTURES
}

\section{Brooks T. Morris}

Introduction--There now exists in theoretical analyses, in laboratory findings, and in conventional engineering-design practice, a skeleton of facts on which a rational scour-control procedure can be based. The writer has assembled these facts and stated them in as straightforward a manner as, he believes, is consistent with current knowledge. Examples of the manner in which the analysis is taken into account in ordinary engineering design are given in support thereof.

Scour--Scour-control procedures should be planned with attention to the details of the scourphenomenon itself. Scour may be defined as the deepening, widening, or shifting of streamchannels under the influence of locally concentrated attack by running water. It is important in hydraulic design primarily in its effect on the safety of structures founded on erodible materials. For instance, if a stream-channel be deepened by scour below a dam, the downstream toe of the structure, normally a point of high stress-intensity, may be undermined by caving, or by percolation-flow, or by both. Such undermining can bring about disintegration of the structure or its foundation and, eventually, the dislodgment, overturning, or collapse of the dam.

Scour can be dangerous to the abutments of a dam, as well. If the channel be widened by scour, caving of the banks may weaken the natural abutments or may shorten the percolationpaths through them sufficiently to bring about sloughing, piping, and complete destruction. Although undermining by scour is only one cause of dam or abutment failure, lack of attention to scour-control has ranked with other types of spillway and foundation inadequacy as a major cause of damage or failure. As the "tighter" dam sites are used up so that more and more structures must be built on permeable foundations, scour-control will become more and more important to dam safety.

Although, scour previously has been treated primarily as a matter of the hydraulics of structures, current practice is to treat scour-control as a problem in the dynamics of streams. Scour is an exceedingly difficult phenomenon to observe in its active phase in nature. Normally, we can observe only its effects after passage of a flood or damage to a structure. It is appropriate, therefore, that specific scour-problems be studied in the hydraulic laboratory and that the general problem be analyzed as a phase of the mechanics of sediment-transportation, a branch of science in which basic data are established in the hydraulic laboratory as well as through fieldobservation.

From the viewpoint of sediment-transportation mechanics, scour may be considered to be the removal of sediment because of local and variable excess of entrainment over deposition. Three possibilities exist concerning the rate of growth of scour-holes; either this excess will increase with the size of the scour-hole, it will remain constant, or it will decrease. The first case is one of instability; sudden and rapid growth will continue as long as that case applies. But that same rapid growth will quickly alter the flow and bring to an end the conditions of the first case. 
The second possibility leads to a constant rate of growth. The third one, ordinarily that most important in the production of large scour-holes, yields a steadily decreasing rate of scour-hole growth in which a condition of equilibrium between entrainment and deposition is approached. At this equilibrium-condition scour ceases and sediment is continuously interchanged between the bed and the stream.

Factors in scour control--The factors that control the ability of a stream to scour and that are significant to our problem may be listed as follows: (1) The amount of sediment brought into the region of scouring action by the stream; (2) the sediment-carrying capacity of the flow in the downstream channel; (3) the resistance of the bed- and bank-materials to dislodgment and entrainment; (4) the mixing or sediment-suspending power of the eddies produced in the scour-zone; and (5) the velocity of flow through the scour-zone.

At present the influence of each of these factors is but partly understood. Their evaluation is absorbing the efforts of a number of hydraulic laboratories, including the Cooperative Research Project of the Soil Conservation Service and the California Institute of Technology. But even without further laboratory work it is apparent that each one of these factors is taken into account in some way or other in conventional scour-resistant designs for hydraulic structures.

Scour-control factors (1) and (2)--The first two factors, sediment-input and sediment-output capacity determine stream-behavior. For instance, the cross-section, elevation, and slope of the bed and banks of the stream existing before a dam or other structure is erected are changing quantities determined by the accumulated effects of factors (1) and (2) during the history of the stream. Aggradation or degradation may be in progress at the time of observation, depending on which factor predominates.

The influence of factors (1) and (2) is normally recognized in the selection of the elevation or grade of the end of the water-carrying portion of the structure and of the depth of cut-off wall, if any is used. The most common practice is to place the end of the structure at or below some stream-bed elevation that may be presumed to exist for the design conditions, and to protect the structure against local and extreme disturbances of the bed by the use of a cut-off wall extending below the depth of any anticipated scour.

Factors (1) and (2) furnish a stream-channel condition on which the local effects of the other factors are superposed. In each of factors (1) and (2), the influences of flow-characteristics and of bed- and bank-material characteristics along the stream-channel are felt.

Factor (3)--The third factor, the resistance of the bed- and bank-materials to dislodgment and entrainment, affects the rate at which sediment particles may be loosened and mixed into the stream. It is determined by several characteristics of the bed-material. In a single-sized, incoherent, granular material such as a well-sorted sand, gravel, or rip-rap material, the size, weight, shape, orientation and packing of the particles determine their resistance to dislodgment. These characteristics determine settling-velocity and, therefore, resistance to suspending action. But other factors may affect resistance to the dislodgment from the bed- or bank-mass that must precede suspension. Particles lying on sloping faces are easier to dislodge than those on the bottom. Particles lying in well-graded beds are more difficult to dislodge than those in beds of sorted material until the fine grains are washed away and sorted from the coarse. Even then, if the coarse particles are sufficiently large and heavy, the formation of a scour-pavement may prevent the removal of finer materials a short distance below the surface. The most extreme resistance, of course, is offered by particles in cemented or tightly packed masses in which either a tensiontransferring agency or resistance to interstitiul flow [see 8 of "References" at end of paper] may prevent rapid removal of surface particles.

These inherent characteristics of bed- and bank-materials have been recognized in several ways in scour-resistant design. In the selection of sites and locations for hydraulic structures, arrangements are made to terminate artificial channels, such as spillways, in stream-reaches lined with the most resistant natural material. Outlets have been designed so as to give better protection to weak materials than is given to scour-resistant sediments. Accumulated engineering experience has produced tables of permissible velocities for channels in various materials.

Rip-rap pavings have been laid both for original work and for repair. The advantages of graded or well-interlocked particles in revetments may be predicted from the added scourresistance of closely packed materials. However, notable failures have taken place when other agencies than surface attack, by disrupting interlocked or cemented pavings, have allowed potholes to form, to grow, and to demolish the whole protective work. 
Factor (4)--The fourth significant factor in scour-control is the mixing or stirring power of the eddies in the scour-zone. This feature of stream-flow produces sediment-suspending power. Local excess of sediment-suspending ability, and thus of transporting ability, over that existing in normal stream-reaches is the most important factor in localized scour. Recognition of the nature of this factor is owed to the application of modern fluid-mechanics to stream-dynamics. At the present time, in sediment-suspension studies, mixing intensity must be experimentally determined for specific conditions. One of the variables determining the amount of sediment suspended by a given eddy-system is the concentration of sediment available for mixing at the point of loading, that is, the bed.

The ability of the stream to remove sediment in suspension from a given zone depends on the mean velocity of the fluid in which the sediment is suspended and on the opportunity afforded for the settling out of the sediment in zones of low-suspending ability.

A number of distinct types of eddies or mixing systems exist in normal channel-flow and in scour-zones. Each of these is occasionally referred to as "turbulence". Rather than a discussion of the scope of that magic word, a description of the sediment-suspending characteristics of particular eddy-motions will be given. In normal channel-flow, there are regular and irregular three-dimensional motions in addition to the mean motion of flow down the channel. Unless the portions of the stream in which such motions exist are identified by foreign material entrained with the water, air-bubbles or soil-particles, for instance, these eddies are not visible. Special instruments are necessary for indication of the regular motions and the irregular motions are apparent only in fluctuations. These motions, for all the difficulty of observing them, must be recognized as those responsible for the maintenance of sediment in suspension in a stream. They result, primarily, from the friction-stresses set up in the flow passing the bed and banks of a stream. The continued formation of eddies and their subsequent decay is the process of energy-dissipation through which the energy "losses" in channel-flow are converted to heat.

More familiar to hydraulic engineers are the eddies set up by individual obstructions to channel-flow or by sharp, sudden, or violent changes in the flow-outlines. These eddies, and others associated with them, but not so easily observed, are responsible for the greatly increased sediment-suspending ability of stream-flow at points of localized scour. Like the eddies of channel-flow, the strong eddies just described are an essential part of the agency by which "lost" energy is taken from the stream.

Factor (5)--It is difficult to give examples of attempts to control eddy-formation without at the same time discussing the fifth factor, the mean velocity of flow through the scour-zone. The magnitude, direction, and distribution of this velocity are important. If the principal flow attacks the bank or bed and is turned by it, pressure-gradients and shear-stresses are set up that loosen particles and that also develop eddy-motion in the flow to aid in suspending the loosened particles. If the principal flow is intense enough near the bottom it may add to scour by increased drag and bed-load motion. Lastly, the principal flow-rate and direction determine the opportunity for sediment, once suspended, to settle back into the scour-hole, for they determine the time available for settling.

Experimental demonstration--Laboratory experiments initiated by N. A. Christensen and Hunter Rouse and continued by the writer serve to demonstrate the importance of the scourcontrol factors to a particular scouring situation. In these experiments, a jet was directed vertically downward onto a submerged bed of well-sorted sand. Regardless of the ultimate intensity of the jet, during the first instant of jet-flow, the jet was simply deflected as it would be by a slab of masonry (Fig. 1). In the corner, the velocity-energy of the stream produced a stagnation pressure, tending to hold the sand-grains down. Only through fluctuations and eccentricities of velocity- and pressure-distribution could grains be loosened under this stabilizing force.

Going away from the corner and downstream the pressure-gradient and the high velocities were soon able to move grains along the bed. The suspending action of the eddies resulting from the shock loss at the bend was relatively unimportant. Particles were transported a short distance and deposited close to the corner. But the removal of even a few grains of sand changed the outlines of the flow (Fig. 2).

The jet then entered a rounded pit and had to turn more than $90^{\circ}$ in order to leave over the growing dune of deposited material. More intense eddies were produced and still the stream was carrying only a small amount of bed-load. As the pit deepened (Figs. 3 and 4 ) the face of the dune of deposited material steepened. When the angle of repose (approximately $30^{\circ}$ ) was exceeded, sliding took place (Fig. 5), the direction of bed-load motion reversed, and suspension became the 

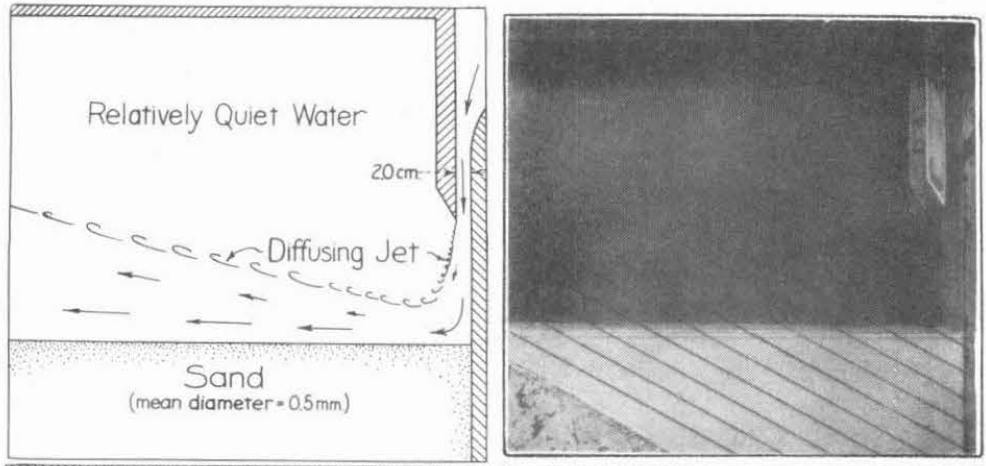

Fig. 1--Form of sandbed during first instant of jet-flow, time one second after start
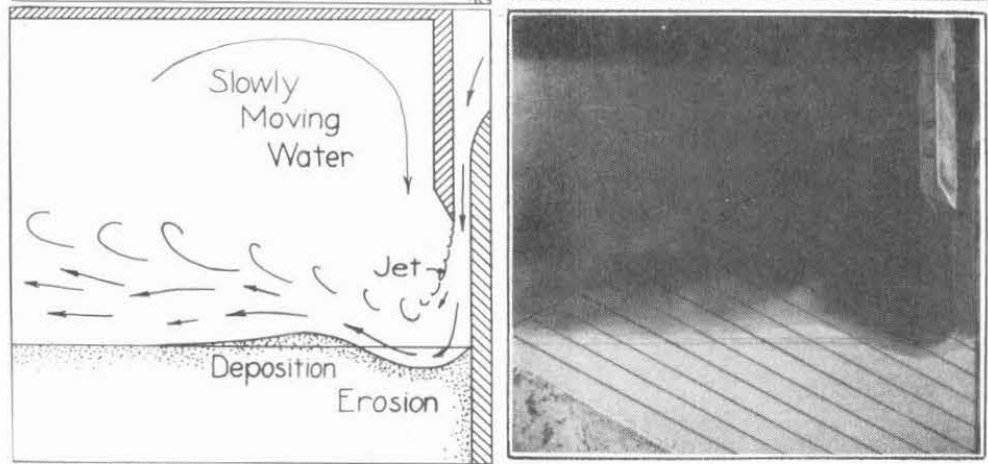

Fig. 2--Scour-pit and deflected jet, time 25 seconds
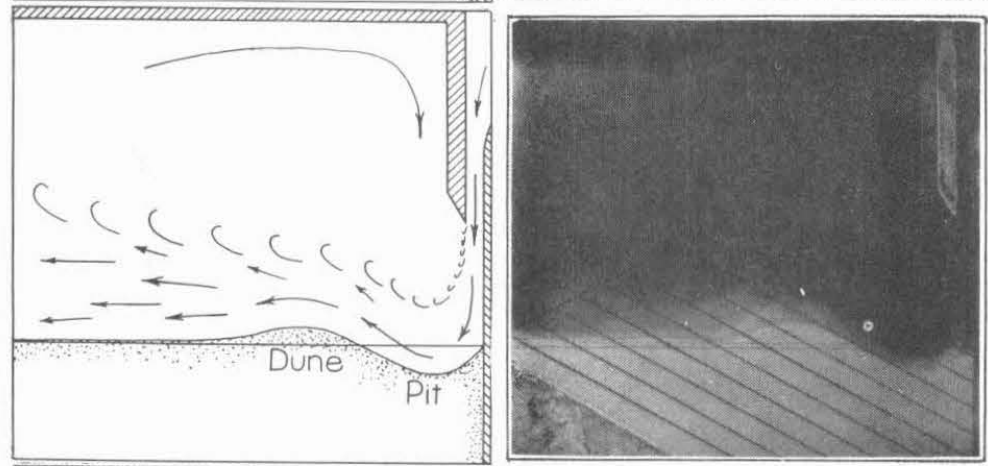

Fig. 3--Growth of scour-pit, time 47 seconds
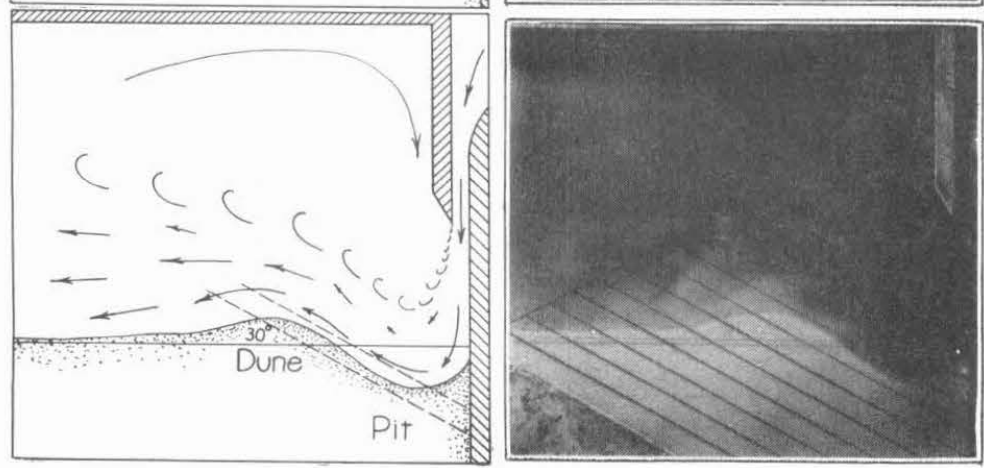

Fig. 4--Scour-pit at maximum size before sliding of dune-face, time 60 seconds

Figs. 1-4--Scour by a submerged jet 

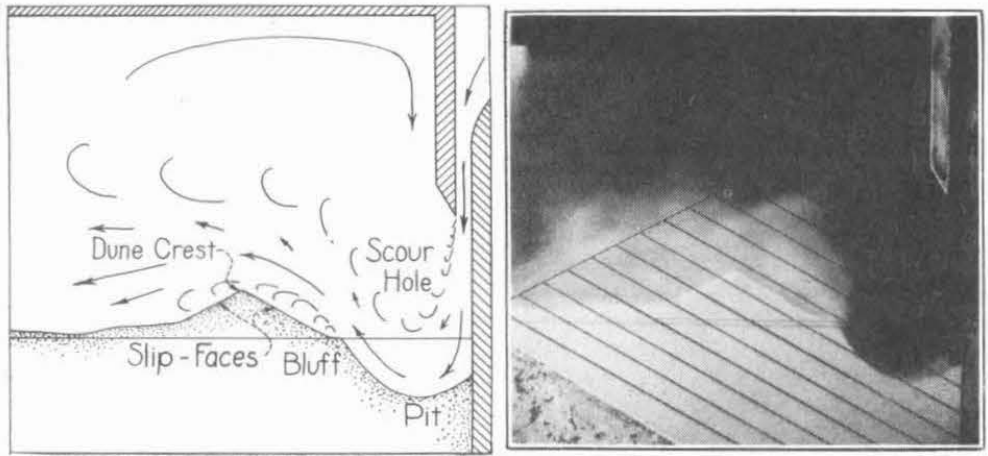

Fig. 5--Formation of slip-faces and loading bluff, time 70 seconds
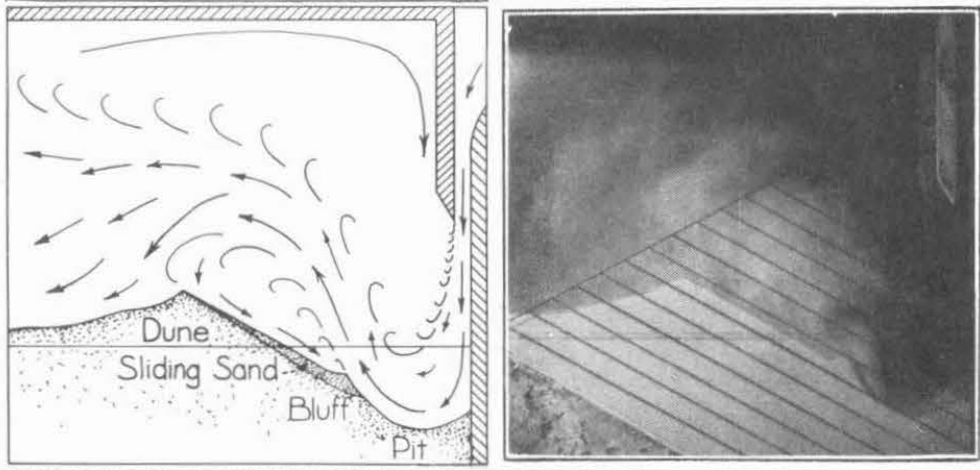

Fig. 6--Fully developed scour-hole pattern (note that suspended sediment, by increasing weight of jet, causes it to flow as a density-current that bends downward as it passes over dune), time 110 seconds
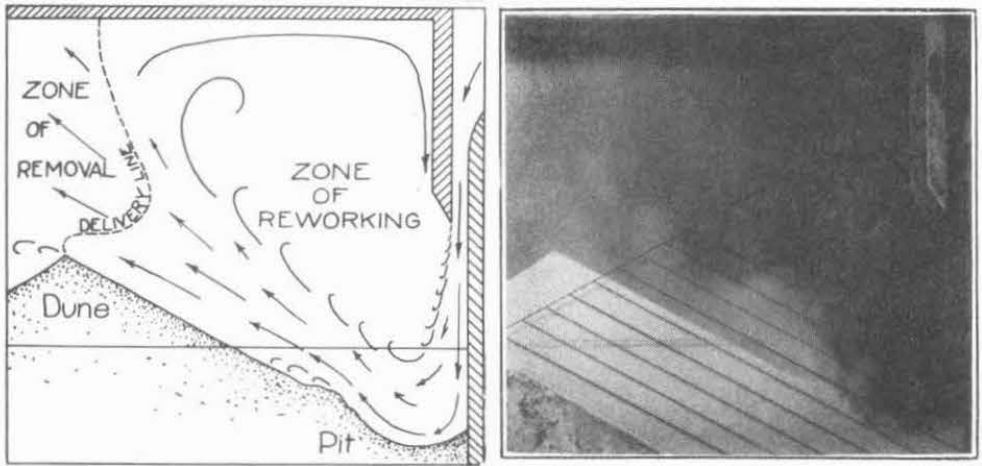

Fig. 7--Advanced stage of scour-hole growth (note increasing distance from loading bluff to crest of dune and thus to deliveryline), time seconds 500

Figs. 5-7--Scour by a submerged jet

only phase of transportation capable of removing sediment over the dune crest (Figs. 6 and 7 ). The mixing system holding particles in suspension was composed of the eddies produced in the scour-pit. The rate of growth of the scour-hole became the rate of removal of particles suspended by the eddy-system.

Let us examine the path of particles from the zone of highest concentration to the point of delivery outside the scour-hole. The greatest loading takes place at the bluff or wave-front where sand sliding down the dune-face (Bagnold's "slip-face") intersects the stream. As we proceed downstream from this point, the rate of deposition exceeds the rate of entrainment and the concentration of sediment in suspension decreases steadily. In short, the rate of transportation decreases in the downstream direction. This decrease is rapid and relatively insensitive to the gross size of the scour-hole, but its influence on scour-hole growth is directly related to scour-hole size. As the hole increases in size and more opportunity is afforded for particles to settle out, the concentration of sediment in the stream passing over the top of the dune becomes 

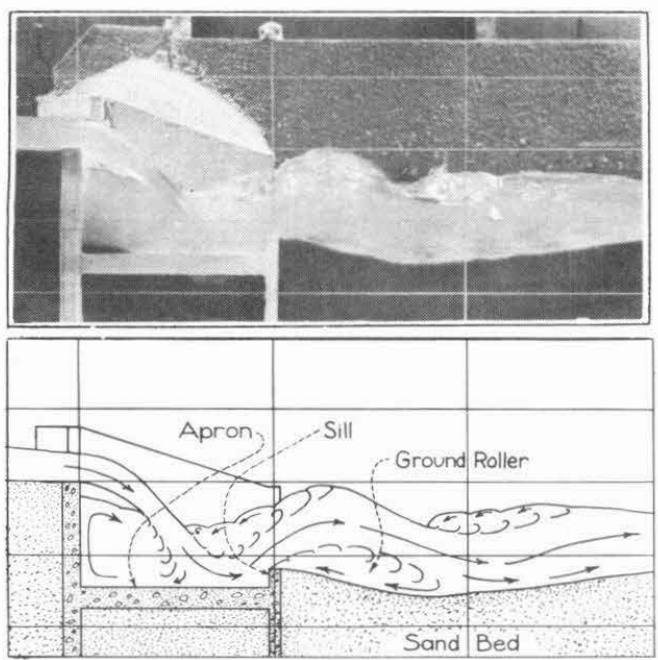

Fig. 8--Ground-roller in a scour-hole (scourhole shown was formed by laboratory model of gully-control drop-structure; scale is indicated by 0.5 -foot spacing of vertical grid-wires) smaller and smaller. The concentration of sediment in suspension in this zone determines the rate of removal of sediment from the scour-hole. The stream leaving the scour-hole and carrying the sediment with it must spread out and change its direction to the horizontal. In doing so it will drop some of its particles upstream from the dune-crest and some downstream. A curved surface (Fig. 7) extending from the crest to the watersurface separates the zones of deposition inside and outside the scour-hole. Only the sediment carried beyond this boundary is removed from the scour-hole. In the increasing distance from the loading zone to the boundary surface, we find sufficient cause for the rapid decrease in scour-hole growth-rate generally observed with increasing scour-hole size.

The preceding analysis of the significance of eddies, suspension, and settling, to scour leads to a simple description of the effect of introducing sediment into the scouring jet. A few experiments have already shown that, at a given stage of scour-hole growth, the rate of transportation of sediment out of the scourhole is changed but little by the introduction of particles of the same sediment in the jet. The most important change produced in the action of the jet is the increase in the sediment-concentration at the point of loading. The sediment in the inflow can increase the output of sediment only by the ratio of the input concentration to the concentration at the loading point in the scour-pit. For scour-holes of appreciable depth and size the loading concentration is many times the output concentration. Therefore, if the sediment input is of the same order that the output was during scour by the clear-water jet, the addition of sediment in the jet will increase the output only slightly. From the discussion of scour-control factors (1) and (2) it is seen that scour-hole growth is only excess of sediment output over sediment input. Therefore, depending on excess input or output, the scour-hole may backfill to reach equilibrium (high input) or grow to reach equilibrium (low input).

In general, the shape and rate of growth of scour-holes are primarily matters of eddyproduction and of velocities as related to the stability of sediment-particles. For steady flow, the control of maximum scour-hole depth and size is owed to the equilibrium of input and output described above, just as the control of grade and elevation in a normal stream-reach is predominantly a matter of sediment input and output. For rapidly changing conditions, however, the duration and variation of sediment input, sediment output, and stream-flow become important. For instance, in short floods or in laboratory studies, the size of the scour-hole may be limited more by flood-duration than by sediment inflow.

Design-use of factors (4) and (5)--Returning now to the description of the use of the principles of eddy-and velocity-control in the design of hydraulic structures, we find in the problem of spillway-design for overflow dams several conspicuous applications. The ideas of protection against direct impact of falling water and of dissipation of its kinetic energy are firmly established. However, a few laboratory workers have made progress beyond these ideas by making a closer approach to the eddy-control principle.

It is possible to discuss the problem of scour-control below spillways in terms of the use of sills and baffles of various types and for various purposes on spillway-aprons. Observation of spillways in which the flow is led off of a horizontal apron at a relatively high velocity onto an erodible bed has shown the need for protection against undermining of the spillway-apron and its subsequent destruction. These are common phenomena pertaining alike to great dams constructed for power-development, to dams for the canalization of rivers, and to grade-control dams in canals and gullies. One of the most successful procedures for combating undermining has been the use of bottom-anchored obstructions to flow, installed for energy-dissipation and flow-deflection. Each such device, be it continuous sill, dentated sill, interrupted sill, baffle or block, produces both effects. But, as has already been pointed out by many, good flow-deflection characteristics are 
not necessarily good energy-dissipation characteristics, and vice versa.

Both flow-deflection and energy-dissipation as accomplished by such devices are phenomena of shock-loss and eddy-production. As such, they have direct and characteristic effects on sediment-suspension and on intensity and distribution of velocity in the region of incipient scour. Separation downstream from transverse sills, baffles, or deflectors, sets up an eddy-system whose regular features are familiarly known as the "ground-roller" (Fig. 8). The scour-control characteristics of a given spillway-design are intimately related to the nature of the flow-pattern and eddy-system produced by the terminal sill of the spillway-bucket or apron.

Even the simple transition from a flat apron to the erodible bed of a stream can develop a ground-roller if a scour-hole is produced at all. In the scour-hole, occupied in part by the groundroller, the direction of flow along the stream-bed varies from upstream to downstream. A peculiar advantage of the ground-roller type of flow is that it contains an upstream motion that is capable of transporting sediment upstream and thus of preventing destructive undermining of the toe of the apron. This advantage is obtained to various extents by the different obstructions that are placed at the downstream-end of the apron. Scour-holes whose shape is controlled by a stable groundroller motion grow in much the same fashion as the laboratory scour-hole previously discussed. Once the ground-roller has been established, no change takes place in the shape of the scour-hole; growth is a matter of increase in scale and downstream shift only.

The reasons that so many different types of sill or deflector have been used are: (1) That varying amounts of energy-dissipation have been intended to suit various conditions of downstream flow and sedimentation, and (2) that attempts have been made to reduce the eddy-intensity of the ground-roller system to the minimum required for protection against undermining. Where the maximum attention has been given to energy-dissipation, a very strong ground-roller may be produced with a scour-hole of desirable shape but of greater depth than might be desired. One particular disadvantage of this type of performance, probably related to the intensity of the groundroller, is the presence of deep scour at the ends of the roller near the banks of the stream.

Interrupted and dentated sills have been tested and used by different individuals and organizations. In each of these devices, some portions of the flow are deflected less than the other portions so that the development of the ground-roller is impaired. From the preceding descripton of the protective action of ground-rollers it should be evident that the upstream direction of flow only, not high upstream velocity, is essential to this process of scour-control. Therefore, any weakening of the ground-roller that is accomplished uniformly enough may decrease the overall eddy-intensity and thus the rate of scour-hole growth and the equilibrium depth of scour. A notable effect of attempts to improve scour-control in this way is reduction in pot-holing near the banks. This finding lends strength to the idea that the eddies that accomplish deep scour near the banks are associated with the ends of the ground-roller.

In some structures the greater part of the energy-dissipating eddy-production takes place near the upstream rather than the downstream-end of the apron. This is particularly true of hydraulic-jump structures in which the tailwater-depth is sufficient to maintain the jump on the apron without the use of auxiliary weirs or baffles. In structures of this type, the terminal sill has primarily the function of flow-deflection or ground-roller control. Therefore, interrupted or dentated, or low, continuous sills have been used with considerable success.

In the discussion of the importance of eddies to scour, most of the attention has been given to irregular motion and to regular or roller motion about horizontal axes transverse to the stream. Less is known about regular vortex motions whose axes are vertical, oblique or horizontal and parallel to the direction of stream-flow. Observation and laboratory study alike indicate that eddies with vertical axes, such as those established near the banks at the end of a spillway, are associated with deep scour. Claims are made for certain types of interrupted sills or baffles, particularly the Rehbock dentated sill, that these devices afford better protection against eccentric velocity-distribution (in plan) and consequent pot-holing from vertical-axis formation than do straight transverse sills. The writer's own experience with longitudinal sills and baffles leads him to believe that the large flat baffle-faces, parallel to the principal stream-flow, of the Rehbock sills may furnish their resistance to cross-flow and to pot-holing. However, the whole matter of the effect of eddies with vertical or oblique axes, or with axes parallel to the streamflow remains a field for pioneer exploration.

Six scour-control principles-In recognition of his own choice of five significant factors in scour-control the writer wishes to propose six basic principles for procedure in the design of scour-control devices as follows: (1) Take into account the sediment passing through the 
structure; (2) reduce the downstream sediment-carrying capacity to a minimum; (3) choose a site with bed and banks of the most stable materials, or increase particle-stability artificially; (4) produce a stable flow-pattern with optimum eddy-orientation and minimum eddy-intensity; (5) reduce flow-velocities to the minimum; and (6) apply each of the first five principles with due regard for the others.

The first five principles have been suggested in direct recognition of the five scour-control factors, respectively. The sixth principle is stated in recognition of the impossibility of applying the preceding five independently. It must be recognized also that one or more of the principles may be inapplicable to a given situation because of inconsistency of that phase of scour-control with the purpose for which the structure is to be built.

The writer has set down certain generalities on scour-control because he believes they may be valuable in directing further research in scour-control, in guiding the location and design of structures, and in analyzing the performance of existing structures. Obviously, the nature of the material he has presented establishes the debt the writer owes to others studying and writing in the field of scour-control. The references cited below have been of particular value to him in formulating his analyses.

\section{References}

[1] R. A. BAGNOLD, Physics of blown sand and desert dunes, Methuen, London, 1941.

[2] A. M. BALLANTYNE, The prevention of erosion at the foot of weirs, Civ. Eng. (London), August, 1938, pp. 287-294.

[3] R. V. BURNS and C. M. WHITE, Protection of dams, weirs, and sluices against scour, J. Inst. Civ. Eng., v. 10 (1), pp. 23-46, November 1938; v. 12 (8), pp. 251-271, October 1939; v. 14 (8), pp. 594-596, October 1940.

[4] A. D. D. BUTCHER and J. D. ATKINSON, The causes and prevention of bed erosion, Proc. Inst. Civ. Eng., v. 235, pp. 175-222 with discussion, 1932-33, Part I.

[5] JOHN R. FREEMAN (Editor), Hydraulic laboratory practice, Amer. Soc. Mech. Eng., New York, 1929.

[6] C. C. INGLIS and D. V. JOGLEKAR, Dissipation of energy below falls, Bombay P.W.D. Tech. Paper No. 44, Bombay 1933.

[7] Notes on experiments carried out with a short-crested weir model, Bombay P.W.D. Tech. Paper No. 51, Bombay 1934.

[8] R. T. KNAPP, A concept of the mechanics of the erosion-cycle, Trans. Amer. Geophys. Union, pp. 255-256, 1941.

[9] M. P. O'BRIEN, Review of the theory of turbulent flow and its relation to sediment-transportation, Trans. Amer. Geophys. Union, pp. 487-491, 1933.

[10] HUNTER ROUSE, Fluid mechanics for hydraulic engineers, McGraw-Hill, New York, 1938, Chapter 14.

[11] Experiments on the mechanics of sediment suspension, Proc. Fifth Internat. Cong. Applied Mechanics, Wiley, New York, 1939, pp. 550-554.

[12] Criteria for similarity in the transportation of sediment, Proc. Hydraulics Conf., Univ. Iowa Studies in Engineering, Bull. 20, pp. 33-49, 1940.

[13] A. SCHOKLITSCH, Stauraumverlandung und Kolkabwehr, Julius Springer, Vienna, 1935.

[14] VITO A. VANONI, Some experiments on the transportation of suspended load, Trans. Amer. Geophys. Union, pp. 608-621, 1941.

Soil Conservation Service, Cooperative Laboratory, California Institute of Technology, Pasadena, California 